\title{
THE USE OF COLLABORATIVE PLATFORMS IN ROMANIA AND EU: A COMPARATIVE VIEW
}

\author{
Elena Ştiubea \\ Doctoral School of Economic Sciences, Faculty of Economic Sciences, University of \\ Oradea, Oradea, Romania \\ elena_stiubea@yahoo.com
}

\begin{abstract}
The term collaborative economy encompasses various activities that have emerged and developed rapidly in recent years through online collaboration platforms. In this article, we will review what the sharing economy means, what are the positive and negative consequences of such a phenomenon, what are the organizations that support the sharing economy. It can be said that the sharing economy is a reconversion of the traditional economy, which supports a society based on sustainability but, at the same time, must be prepared to respond to the challenges and criticisms brought. In the second part, we examine recent trends in the use of collaboration platforms in Romania and in the European Union (EU-28), focusing on general and more specific features regarding the profile of users, the type of services used and the main advantages and disadvantages of the collaborative economy in relation to traditional trade in goods and services. The data used in this analysis comes mainly from the recently published European Commission survey on the use and provision of services through collaborative platforms, as well as from the corresponding survey previously published in 2016 on the same topic.
\end{abstract}

Keywords: sharing; platforms; advantages and disadvantages; type of services; EU, Romania

JEL classification: $\mathrm{O} 35$

\section{Introduction}

The last decade has represented for the present society a transformation from traditional systems to digital systems, supported of course by the worldwide development of the Internet. At the same time, the last decade is marked by significant economic fluctuations, such as the economic crisis of 2008 , climate change, due to the contemporary lifestyle, with immense consequences on the environment, but also from the fear of the population for the depletion of certain resources. In addition to technological developments, increasing urbanization has also made it possible to bring together a large number of economic actors to develop joint activities. The concentration of people living in the immediate vicinity of the big urban agglomerations has expanded the opportunities for exchange of activities in the common economy, and the digital progress has facilitated the contact between the remote participants.

\section{Theoretical overview}

The concept of "sharing economy" is a consequence of the massive and accelerated digitalization of the contemporary society and at the same time it can be an answer to the current problems of the society. As Belk (2014) stated, the sharing economy was born with the emergence and development of the Internet worldwide, but the idea of "collaborative consumption" appeared long before the emergence and development of the Internet. In 1978 Felsin and Spaeth (1978) sought to research common activities and social 
consumption. They considered that buying a container of beer in common was more cost-effective than purchasing individual glasses (Felsin and Spaeth, 1978).

In the current context, the definition of this phrase has been made by both academics and practitioners. The first author to discuss the topic of sharing economy was Ray Algar, in 2007, in his article entitled "Collaborative consumption" (Algar 2007) in the Leisure Report newsletter. However, the topic became popular only in 2011, when Botsman and Rogers published their book "What's Mine Is Yours: The Rise of Collaborative Consumption" (Bostman and Rogers, 2010). Koen Frenken, a professor at Utrecht University, defined the collaborative economy, in his 2017 paper entitled "Putting the collaborative economy in perspective", as that economy where: "consumers who grant each other temporary access to used physical assets (capacity inactive), possible for money" (Frenken and Schor, 2017). A crude definition of sharing economy can be the exchange of goods or services between two or more individuals, facilitated by an online platform. The People Who Share, an organization that advocates for this type of economy defines sharing economy as " $A$ socio-economic ecosystem built around the sharing of human and physical resources. It includes the shared creation, production, distribution, trade and consumption of goods and services by different people and organisations" (Matofska, 2019). Analyzing the last definition, it can be said that people, especially modern consumers, have more practical thinking and are more oriented towards the benefit/satisfaction that a product or service can offer than ownership over them. Sharing economy comes to meet them, offering a fast and cheap way to adapt the demand with the supply of goods and services (Coyle, 2016).

Although, in the last period, the sharing economy has started to become a popular field of research for academics and practitioners (Arcidiacono et al., 2018, Kumar et al., 2018) and a number of definitions have been elaborated, there is not yet a universally accepted definition (Dredge and Gyimóthy, 2015; Görög, 2018). An argument in this regard could be that the sharing economy covers a very wide range of domains that includes many types of platforms or modes of sharing, these differences leading to inconsistencies in the way researchers conceptualize this phenomenon (Habib et al., 2016).

The study of sharing economy by academics was generally unclear and heterogeneous and there was no agreement regarding the terms used when it comes to this economic model. Thus, in the specialized literature referring to the sharing economy we find phrases such as "collaborative consumption" (Botsman and Rogers, 2010), "product service systems" (Mont, 2002) or "access-based consumption" (Bardhi and Eckhardt, 2012). This was also due to the very rapid evolution of the last years, which prevented the emergence of a common terminology.

Sharing economy is spreading globally at an accelerated pace. If at first the sharing economy gained the greatest popularity in developed countries such as USA, UK or Australia, lately developing countries have already started to adopt the new economic model. In addition, countries with a medium-sized economy have great potential to benefit from collaborative practices to attenuate the lack of access to resources. Companies such as Airbnb and Uber have already entered the markets of Latin America, Asia, the Middle East and Africa (Perren and Grauerholz, 2015), while local entrepreneurs have developed businesses to solve problems such as access to education and financing. The sharing economy communities are formed with the explicit purpose of facilitating the economic exchange of goods and services between people and rarely pay special attention to the brand.

Around this phenomenon, a multitude of opinions have been created, some of which come to encourage and praise this economic model, others but express their disagreement and criticize how it influences the market and society. Regardless of the opinions, it is clear that this topic has managed to stir up a succession of polemics.

Among those who support sharing economy are Bostman and Rogers. They bring to the fore the benefits that this economic model has on the underutilized assets. For example, most of 
the power drills are used for less than 13 minutes throughout their life cycle (Botsman and Rogers, 2010); when consumers have the opportunity to rent or sell a good / service to other consumers, the impact on the environment can be reduced, while maximizing its use over the life of the product. In short, the sharing economy can result in more sustainable consumer behaviors that benefit individual consumers, businesses and society (Botsman and Rogers, 2010). The benefits of sharing economy on the environment are also noted by Firnkorn and Müller, 2011. In their work "What will be the environmental effects of new free-floating car-sharing systems? The case of car2go in UIm", they argue that sharing and cooperation allow a more intensive use of assets, offering a better "leverage" of the natural capital that is "trapped" in a particular product. If we refer to the environment, the common economy is promoted as a sustainable solution (Firnkorn and Müller, 2011).

In addition to the benefits offered, the sharing economy also faces significant challenges: from the balance to be found between market experiences and truly non-profit experiences and those from person to person ( $\mathrm{p} 2 \mathrm{p}$ ), to the attempts to avoid new inequalities and socio-economic exclusions; from the innovative impulse to the arrangements and the logic of the business organization to the coexistence and mutual exchange with the existing organizations; from the ability to build new communities and new forms of relationships to the risks related to the formation of possible transnational communities.

Even though the sharing economy is a model that has many advantages and supports a sustainable lifestyle, there are also opinions that do not support this idea.

Edelman et. al. (2015) raise in their work problems related to discrimination, to the right of ownership over the data, the possibility of selling, sharing, evaluation. No institution has real-time information about what generates online platforms, if the rights of each individual are respected, this being criticized by the authors in their work on sharing economy.

Although sharing economy has a high potential, based on sustainability, to lead to economic growth, this phenomenon is framed in contradictory ways. While some researchers applaud this idea, others believe that over time this phenomenon would lead to market destabilization and negative effects on the economic system (Schofield, 2014). Morozov argues that it is a form of "neo-liberalism on steroids" that markets the aspects of previous life beyond the reach of the market (Morozov, 2013). Schofield criticizes the idea of Airbnb and Uber, concepts based on sharing economy, considering that it opens the way to unregulated markets, from person to person, with a strong negative social impact (Schofield, 2014). Another criticism of the sharing economy is that those who benefit from income as a result of participating in the activities included in this category also have another source of income. As a percentage, only $30 \%$ are those that are based solely on income from sharing economy activities (Schor et al., 2014). Many activists do this only to increase their income and to afford more expensive goods or services. This only deepens social inequalities from the middle class to those with very low incomes. Another criticism of the sharing economy is the idea that it would "steal" the jobs of people without higher education. Thus, in the field of transport of uber drivers, the majority having higher education are taking over the work of taxi drivers, most of whom have average education. Similarly in the area of accommodation, Airbnb takes over a significant part of the people who previously looked for accommodation in hotels. This leads to restructuring in terms of the workforce required in a hotel, and those who suffer the most are all those with average education or workers, such as cleaning staff (Badulescu and Badulescu, 2012), (Badulescu et al, 2014).

The lack of solid regulations in the field is another reason for criticism of the sharing economy. Even though its ascension at an alert pace and the vast areas in which it was applied were an impediment in the elaboration of regulations in this field, it is not an excuse for the absence of elementary rules. However, its regulation, in particular, in accordance with European Union law, is a real challenge. Critics are also taken in the direction in which the definition of platforms as markets has important legal consequences: the rules for service providers are rejected as having no object (they are immaterial), and the public authorities 
are required to apply the regulation only for individual providers. Therefore, only the users are responsible for providing reliable services, as the platforms are not part of the individual-to-individual transactions (p2p) nor are they responsible for breaching the contract or illegal conduct by the parties.

The polemics created around this topic are only part of the multitude of opinions that will follow on this topic.

Despite the criticism, sharing economy includes, for example, transactions through platforms such as Airbnb and BlaBlacar, as well as Uber and TaskRabbit activities. Companies that own such platforms in this market serve as intermediaries between a person providing a service and the person receiving this service (Perren and Grauerholz, 2015). Each actor in this triangle is interdependent and actively involved in the co-production of a unique consumer experience. It is important to note that the roles of companies, sellers and consumers may differ from market types (for example, some require purchases and contact sellers directly, and other buyers and sellers do not have contact; some companies assume responsibility if one product or service fails, others do not). Thereby, collaborative consumer markets are more dynamic, flexible and less institutionalized than traditional markets.

In addition to technology, what has facilitated and propelled the development of the sharing economy is the involvement of companies that facilitate exchange between individuals. Older, established companies, such as Craigslist and eBay, have joined other companies that serve to connect or facilitate exchanges from person to person. These companies are increasing in number, size and profit, which emphasizes the openness of people to new ways of purchasing products or services.

The collaborative economy is characterized by a number of stakeholder groups that can be broadly divided into the following interdependent and overlapping groups described below (Dredge et al., 2016). These groupings are not exclusive for actors may belong to more than one group and move between groups over time. Their interests may also coalesce or conflict depending on the social, economic, political and environmental factors at play. While these groupings are indicative, they are nevertheless useful in conceptualizing the relational setting of the collaborative economy.

\section{Trends in the use of collaboration platforms in Romania and in the European Union}

The evolution of technology and high-speed networks, as well as the increase of social networks and the increase of EU citizens' access to the Internet, have played a significant role in the development of the collaborative economy, digital platforms and other related applications in recent years.

The question is whether the new trend is accepted and embraced in Romania, as well as in the European Union. At the same time, we aim to follow the advantages and disadvantages of using collaborative services. Another question concerns the type of collaborative services that users use.

The way in which the sharing economy is viewed by citizens at European level, how to use it and at the same time the characteristics of users in Europe are recorded in two studies conducted by the European Commission in 2016 and 2018. The study was conducted on a representative sample of the population of the European Union, the minimum age of the respondents was 15 years, and the number of respondents at EU level was 14050 in 2016 and 26544 in 2018 (European Commission, 2016, 2018). According to the results of these surveys, in $2018,23 \%$ of respondents in Romania stated that they used services offered through collaborative platforms. If we refer to 2016, when the percentage of use of these services was $20 \%$, we can see that the trend is increasing, even if the percentage was only $2 \%$. If we make a comparison between Romania and the EU average (for 2018) of respondents who used these types of services we can see that the percentage is identical, which means that in our country people have begun to become receptive to this new 
concept. If we make a comparison between the EU average in 2016 and the one in Romania, we see that in Romania the percentage is higher, respectively $20 \%$, compared to $17 \%$ registered at EU level. From this data it can be said first of all that in Romania these platforms have been well known in 2016, while in the same year in countries such as Cyprus (2\%), Malta (4\%), Czech Republic (7\%), Greece (9\%) the number of those who used these platforms is very small. Even in developed countries such as the Netherlands, the percentage of people who have used these services is not very high, respectively $12 \%$. Secondly, the fact that people have been looking for alternatives to traditional services may also indicate that Romanians are looking for more easily accessible and advantageous services from an economic point of view, which can be seen in Figure 3. In 2018 Romania was on an upward trend in the use of collaborative platforms, not registering large differences in this period, while if we look at the percentage of other EU countries we can not say the same. In the Netherlands, for example, as mentioned above, the percentage was $12 \%$ in 2016, and in 2018 it had a significant increase of $18 \%$ reaching $30 \%$ of the respondents using collaborative platforms. Significant increases were also in Malta reaching $35 \%$ in 2018 or in Belgium 18\%. In 2018 in Romania the percentage of users was identical to the EU average, respectively $23 \%$, which means that the services offered by collaborative platforms were neither the least used by Romanians, nor used very much. In EU countries, the percentages in 2018 were between $17 \%$ in Portugal and reaching up to $40 \%$ in Latvia.

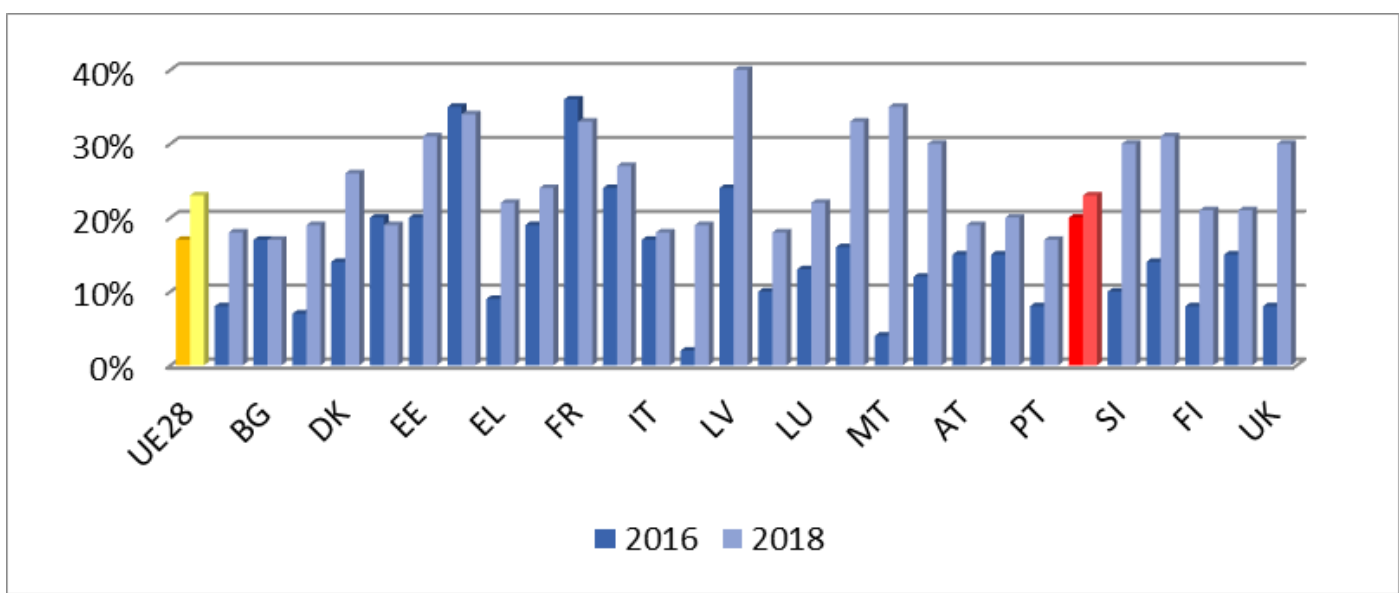

Figure 1: Individuals who use the services of collaborative platforms (percentage of respondents) in 2016 and 2018

Source: European Commission (2016, 2018) Flash Eurobarometer 438 and 467.

\subsection{The type of services used through collaborative platforms}

If we refer to the type of services offered through collaborative platforms, the most often used among respondents are accommodation services (rentals of apartments, houses, etc.) and transport services (figure 2). 


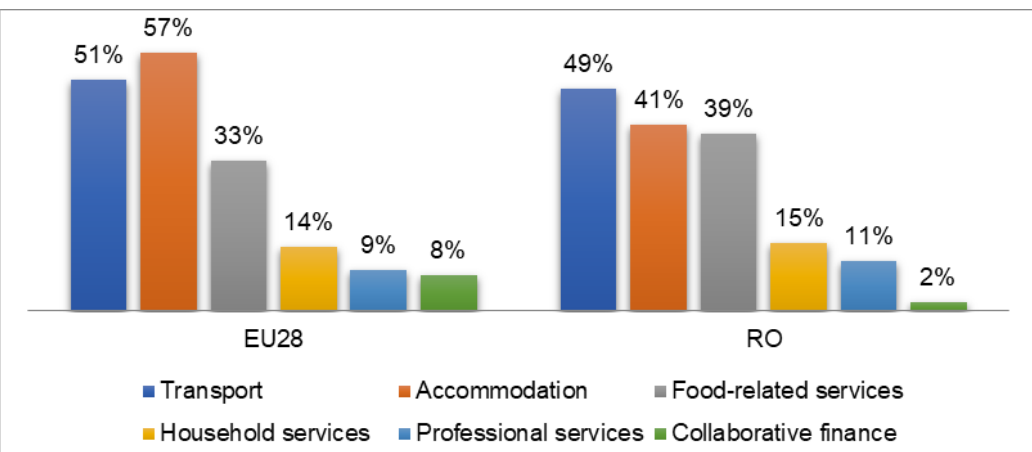

Figure 2: Type of service offered via collaborative platform related to the population that used collaborative services

Source: European Commission (2018), Flash Eurobarometer 467

For example, in Romania in $2018,49 \%$ of users stated that they used transport services, the EU average of the same service being $51 \%$. In the EU, accommodation was used the most, as an alternative service to the traditional ones, a percentage of $57 \%$ of the respondents, while in Romania only $41 \%$ declared that they used accommodation services. In parallel in the same year, 2018, 33\% of food-related services were used in the EU, while in Romania they registered a higher percentage of $39 \%$. Household services also registered a higher percentage in Romania than the EU average. If in the EU the percentage for these services was $14 \%$, in Romania it was $15 \%$. Professional services (IT services, accounting, consulting, etc.) were used by $11 \%$ of respondents, while in the EU by $9 \%$. The $9 \%$ EU-wide percentage is due to the fact that in some member countries these services have not been used at all. If we refer to the collaborative financing services, it can be seen that both at the EU level and at the Romanian level, the percentages are not very high $8 \%$, respectively $2 \%$. This is due in part to their ignorance of their services, but also to their distrust of such a service.

\subsection{The advantages of using collaborative platforms}

The advantages given by the collaborative economy are numerous and can be treated as a separate article, but based on the answers given by users in the survey conducted by the European Commission we can make a ranking of the six most important advantages, both in the EU and in Romania (Fig. 3).

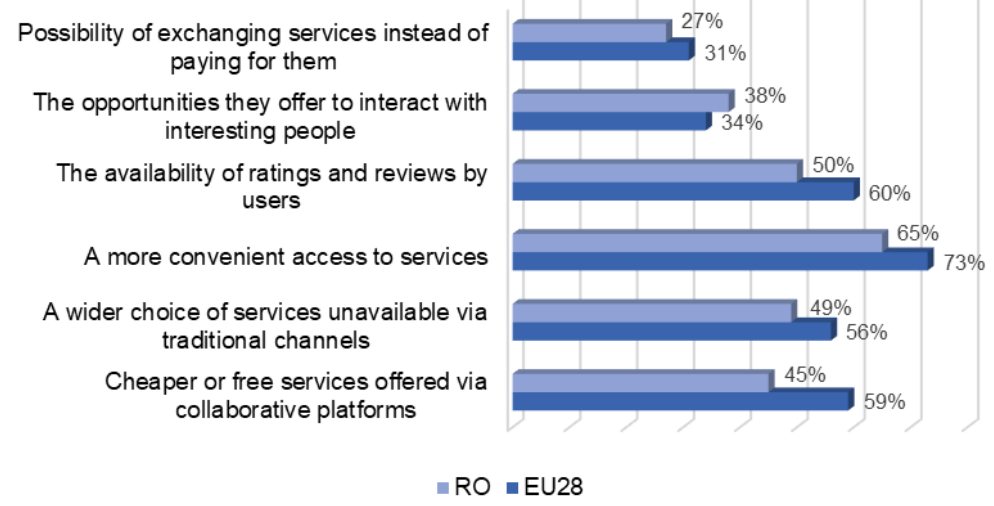

Figure 3: Advantages of using collaborative platforms

Source: European Commission (2018), Flash Eurobarometer 467. 
Thus, most of the European users stated that the most important advantage of collaborative platforms compared to the traditional means is the easy and convenient access to them, $73 \%$ of the respondents being of the same opinion. The Romanians also considered all this advantage to be in the first place, and the percentage in which they answered is $65 \%$. The next important advantage for both Europeans and Romanians is "the availability of ratings and reviews by users". Thus, $60 \%$ of EU respondents considered that this advantage is an important one in choosing a collaborative service and $50 \%$ of Romanians relied on the same idea. At EU level, the third most important advantage is that the services offered through collaborative platforms are cheaper, with $59 \%$ of respondents saying so. In Romania, however, the third most important advantage is a wider choice of services unavailable via traditional channels, $49 \%$ of respondents responding in this regard. In the case of the EU, the advantage considered by the Romanian respondents as being on the third place, at EU level it is considered the fourth with a percentage of $56 \%$, and what the EU considers as the third place advantage, in Romania is on the fourth place as important with a percentage of $45 \%$. The last two advantages correspond to the ranking, both at EU level and Romania, with percentage differences. Thus, the fifth most important advantage is considered to be "the opportunities they offer to interact with interesting people", 34\% in the EU and 38\% in Romania. On the last place of importance is the advantage with reference to the possibility of exchanging services instead of paying for them, $31 \%$ in the EU and $27 \%$ in Romania.

It can thus be observed that the order of advantages at EU level is the same as in Romania, with one exception. At the same time, the most important advantage in both situations is the ease with which these services can be accessed, in a world where time is an important element.

\subsection{Main disadvantages of using collaborative platforms}

The most important six disadvantages given by the collaborative economy, both in the EU and in Romania, are presented in the figure 4.

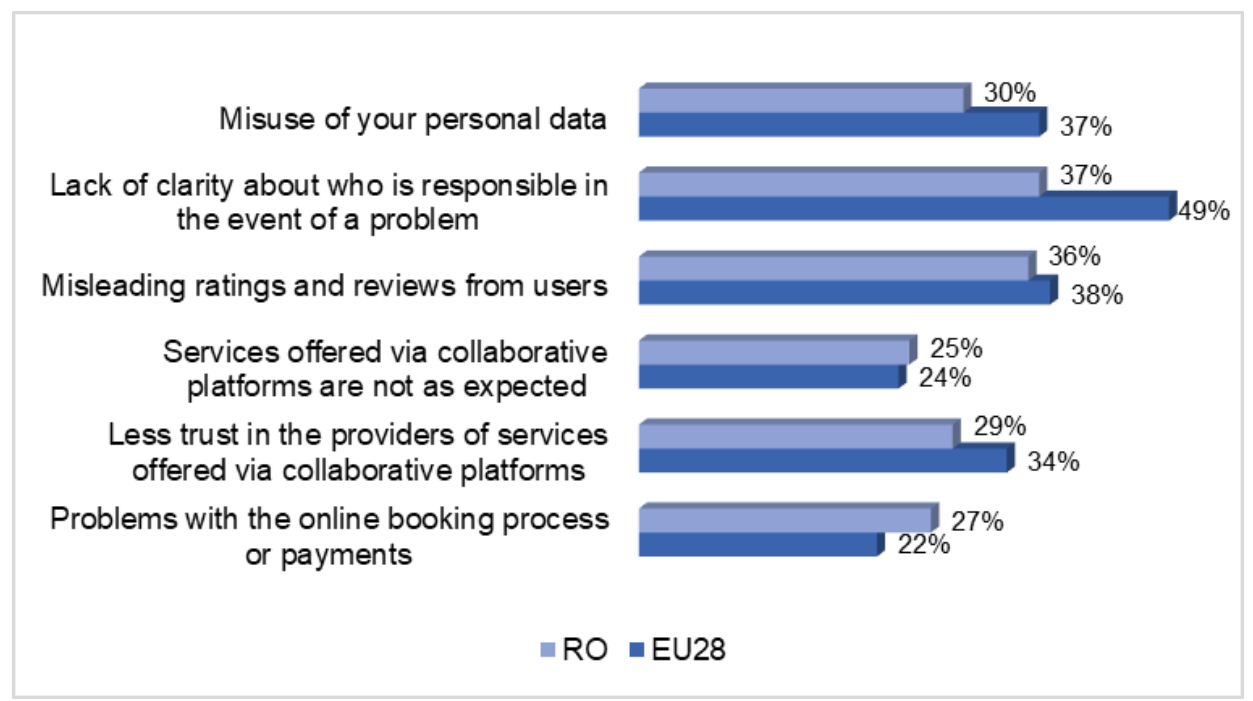

Figure 4: Disadvantages of using collaborative platforms

Source: European Commission (2018). Flash Eurobarometer 467. The use of collaborative platforms

The main disadvantages reported by users of collaborative platforms compared to traditional channels were, in the case of Romania for 2018, lack of clarity about who is responsible in the event of a problem $37 \%$, and in the EU the same disadvantage is considered the most 
important, but in a proportion of $49 \%$. A second disadvantage of collaborative platforms is given by misleading ratings and reviews from users. In Romania, 36\% of respondents reported this problem, and in the EU 38\%. Another problem identified with respondents is the misuse of your personal data. Both Romanians (30\%) and EU residents (37\%) considered that the misuse of personal data brings disadvantages to the new services based on collaboration. $29 \%$ of the Romanian respondents and $34 \%$ of the respondents of the member countries stated that they have less trust in the service providers offered via collaborative platforms. This may be due to mistrust in such services, but also to the lack of proper documentation on this topic. Respondents in Romania considered $27 \%$ that the fifth disadvantage of using collaborative services is "problems with the online booking process or payments", while in the EU the fifth disadvantage in proportion of $24 \%$ is services offered via collaborative platforms are not as expected. The last disadvantage, according to the survey, in Romanian (25\%) refers to services offered via collaborative platforms are not as expected. At EU level, problems with the online booking process or payments are considered to be the biggest disadvantage with a percentage of $22 \%$.

We can see that problems similar to those in Romania were registered at the level of the entire EU, but with small differences in ranking and of course in percentages.

\section{Conclusion}

The "sharing economy" and "collaboration economy" encompass various activities that have emerged and developed rapidly in recent years through online collaboration platforms. A common feature of these activities is the mediation of online collaboration platforms that link users and service providers, in order to use(share) more efficiently natural or human resources.

Romania follows the international trends of increasing the use of collaboration platforms, presenting, according to the relevant survey of the European Commission, an increase in the share of users in the population (from $20 \%$ in 2016 to $23 \%$ in 2018). As a result, Romania has now reached the EU-28 average of 23\% in 2018). Regarding the type of services used, the main sectors of activity in Romania and at EU level are transport and accommodation, the EU average exceeding both in transport (49\% Romania, 51\% EU) and in accommodation (41\% Romania compared to $57 \%$ EU).

User perceptions of the advantages and disadvantages of using the services through collaboration platforms seem to converge in Romania and the EU, with the most frequently reported advantages being identified in terms of rating availability, cheaper or free services offered and a wider range of options. The most common disadvantages mentioned are the lack of clarity about who is responsible in the event of a problem, misleading assessments and reviews, misuse of personal data and lack of trust in the service provider.

Of course, there are several motivations and variables that influence the use of online platforms in Romania and at EU level, but being a more theoretical model has its obvious limitations. In addition, a more detailed study of these motivations and not only will be the subject of future studies

\section{References}

Arcidiacono, D., Gandini, A., and Pais, I., 2018. Sharing what? The 'sharing economy' in the sociological debate. The Sociological Review Monographs, 66 (2), pp. 275-288.

Badulescu, A. and Badulescu, D., 2012. Entrepreneurship and Local Resources. In D. Leslie, 2012. Tourism Enterprises and the Sustainability Agenda across Europe. UK: Ashgate Publishing, pp. 151-168.

Badulescu, A., Badulescu, D. and Borma, A., 2014. Enhancing cross-border cooperation through local actors' involvement. The case of tourism cooperation in Bihor (Romania) - 
Hajdú-Bihar (Hungary) Euroregion. Lex Localis - Journal of Local Self-government, 12 (3), pp. 349-371.

Bardhi, F., and Eckhardt, G., 2012. Access-Based Consumption: The Case of Car Sharing. Journal of Consumer Research, 39(4), pp. 881-898.

Belk, R., 2014. You are what you can access: Sharing and collaborative consumption online. Journal of Business Research, 67, pp. 1595-1600.

Botsman, R., Rogers, R., 2010. What's Mine Is Yours: The Rise of Collaborative Consumption. New York: HarperCollins.

Coyle D., 2016. The Sharing Economy in the UK, [online] Available at: <http://www.sharingeconomyuk.com/perch/resources/210116thesharingeconomyintheuktp dc.docx1111.docx-2.pdf> [Accessed on 27 February 2020].

Dredge, D. and Gyimóthy, S., 2015. The collaborative economy and tourism collaborative economy and tourism: Critical perspectives, questionable claims and silenced voices. Tourism Recreation Research, 40 (3), pp. 286-302.

Dredge, D., Gyimo'thy, S., Birkbak, A., Jensen, T. E. and Madsen, A. K., 2016. The impact of regulatory approaches targeting collaborative economy in the tourism accommodation sector: Barcelona, Berlin, Amsterdam and Paris. Impulse Paper, 9. Brussels: European Commission.

Edelman, B., Luca, M., and Svirsky, D., 2015. Racial Discrimination in the Sharing Economy: Evidence from a Field Experiment. HBS Working Paper, 9 (2), pp. 1-22.

European Commission, 2016. Flash Eurobarometer 438: The use of collaborative platforms, [online] Available

at: http://ec.europa.eu/COMMFrontOffice/PublicOpinion/index.cfm/ResultDoc/download/Docu mentKy/72885 [Accessed on 26 February 2020].

European Commission, 2018. Flash Eurobarometer 467: The use of collaborative economy, [online] Available at: https://data.europa.eu/euodp/en/data/dataset/S2184 467 ENG [Accessed on 26 February 2020].

Felson, M. and Speath, J., 1978. Community structure and collaborative consumption. American Behavioral Scientist, 21 (4), pp.614-624, [online] Available at: https://pdfs.semanticscholar.org/fd33/73fa4e7b1a9a65352d1998be01c2021ccddc.pdf? ga $=2.46042406 .388251180 .1583225654-407571271.1572897768$ [Accessed on 03 March 2020]

Firnkorn, J., and Müller, M., 2011. What will be the environmental effects of new free-floating car-sharing systems? The case of car2go in Ulm. Ecological Economics, 70 (8), pp. 1519-1528.

Frenken, K., and Schor, J., 2017. Putting the sharing economy into perspective. Environmental Innovation and Societal Transitions, 23, pp. 3-10, [online] Available at: http://doi.org/10.1016/j.eist.2017.01.003 [Accessed on 23 February 2020].

Görög, G. (2018). The definitions of sharing economy: A systematic literature review. Management, 13 (2), pp. 175-189. doi:10.26493/1854-4231.13.

Kumar, V., Lahiri, A., and Dogan, O., 2018. A strategic framework for a profitable business model in the sharing economy. Industrial Marketing Management, 69, pp. 147-160.

Perren, R. and Grauerholz, L., 2015. Collaborative Consumption. International Encyclopedia of the Social \& Behavioral Sciences, (Second Edition), Elsevier, pp. 139-144. Matofska B., 2019. Generation Share: The Sharing Economy is saving millions of lives worldwide, [online] Available at: https://www.thepeoplewhoshare.com/blog/generation-share-sharing-economy-saving-millio ns-lives-worldwide [Accessed on 07 March].

Morozov, E., 2013. The 'sharing economy' undermines workers' rights, [online] Available at: http://evgenymorozov.tumblr.com/post/64038831400/the-sharing-economyundermines-wor kers-rights [Accessed 01 March 2020] 
Schofield, H., 2014. Short-let apartments spark Paris row as Airbnb thrives, [online] Available at: http://www.bbc.co.uk/news/world-europe-30580295 [Accessed on 28 February 2020].

Statista, 2020. Number of Airbnb users in the United States from 2016 to 2022. [online] Available at: https://www.statista.com/statistics/346589/number-of-us-airbnb-users/ [Accessed on 28 February 2020].

\section{Bio-note}

Elena Ştiubea, is Ph.D. student at University of Oradea, Faculty of Economics Sciences. Her research interests include general aspects of sharing economy and her main focus for the $\mathrm{PhD}$ research is the impact of sharing economy on tourism. 